\title{
Agile Methods in Ethiopia: An Empirical Study
}

\author{
Zelalem Regassa $^{1}$, Julian M. Bass $^{2}{ }^{\bowtie}$, and Dida Midekso ${ }^{1}$ \\ 1 Addis Ababa University, Addis Ababa, Ethiopia \\ zelalem.regassa@aau.edu.et, mideksod@yahoo.com \\ 2 University of Salford, Salford, UK \\ j.bass@salford.ac.uk
}

\begin{abstract}
This paper provides empirical evidence of agile method adoption in smaller companies in Ethiopia. Agile methods are emerging as best practice for software development in the global north. So, is there evidence that agile methods are being used in Ethiopia? A Grounded Theory approach was adopted using face-to-face interviews with 17 software professionals from 7 software companies, which were selected by using a snowball sampling technique. The interviews were semi-structured and open-ended and have been audio-recorded, transcribed and analysed. It was discovered that agile principles, values and practices are important to study participants. Agile practices are used to encourage user participation and clarify requirements. However, it was found that many projects are for government clients that mandate extensive requirements and design documentation which must be approved prior to delivery of working software that complies with predefined delivery schedules.
\end{abstract}

Keywords: Agile, Small and Medium-sized Enterprises, Ethiopia

\section{Introduction}

Software development has a key significance for developing countries to harness IT opportunities for their socio-economic growth [27]. In particular, the development of local software industry can provide a number of opportunities for developing countries of Africa. By utilizing the relatively low cost base in Africa, it can create economic growth through export earnings and it can provide employment opportunities for the increasing number of skilled graduates. Moreover, locally developed software is a lot cheaper and can better address the unique contextual requirements of developing countries than software from external sources.

In recent years, agile methods have emerged as an alternative potential solution to problems of information system development [28]. The overall principles underpinning the agile approaches emphasizes individuals and interactions over processes and tools; working software over comprehensive documentation; customer collaboration over contract negotiation; and responding to change over following a plan. Agile methods belong to the latest class of iterative and evolutionary software processes [7]. Agile methods employ 'short iterative cycles, 
actively involve users to establish, prioritize, and verify requirements, and rely on a teams tacit knowledge as opposed to documentation' [8]. The significance human and social factors for the success of information system development are at the centre of agile methodologies. As a consequence, agile methods increase flexibility in the face of evolving requirements, improve productivity, and enhance product quality [17].

There is a paucity of research literature on agile information system development in the global south and previous studies have been dominated by researchers from the global north. There is lack of empirical data on information system development practices used by African software companies. Comparatively little is known about how African companies develop information systems and what challenges they face during software development. This paper contributes to filling this gap.

The structure of this paper has four sections. Section 1 presents the introduction. In section 2, previous studies have been discussed. Section 3 and Section 4 present the research methods and research findings respectively. Sections 5 and 6 provide discussion and conclusions of the paper respectively.

\section{Related Work}

Agile methods are adopted by software development organisations in a series of assimilation stages [28]. Initial acceptance is where there is a commitment to use agile practices, either by the book or in some tailored fashion. During routinisation, agile practices are frequently used, highly embraced and adhered to. While in the infusion stage agile practices are used in an even more in a comprehensive or sophisticated manner.

The critical success factors of agile software development projects include: (a) a correct delivery strategy, (b) a proper practice of agile software engineering techniques, and (c) a high-calibre team, (d) a good agile project management process, (e) an agile-friendly team environment, and (f) a strong customer involvement [13]. It has been argued that there was lack of evidence on some assumed prerequisites for success of agile projects to be considered critical factors for success. They include strong executive support, strong sponsor commitment, ready availability of physical agile facility, or agile-appropriate project types, etc.

Agile method tailoring, which involves selecting methods or practices depending on local context [9], has become well documented [18]. There is a trend away from wholesale adoption of XP practices [15], towards adoption of scrum [3], while smaller companies tend to cherry-pick' selected Scrum and XP practices from the full constellation of practices available [14]. While software development methodologies for developing countries should consider the social, cultural and technical context [6]. Such an approach might draw upon lean UX (user experience), participatory design and action research methods. 
Agile requirement engineering practices can be used to address challenges with customer involvement and cross-functional teams introducing new approaches to requirements management and requirements review sessions [20].

The use of the Scrum agile methodology can improve software development project productivity, customer satisfaction, product and process quality, team motivation, and cost reduction[11]. Scrum practices are often used in conjunction with other software development practices, for example in large-scale business information system development both project roles [4] and the artefacts produced are tailored [5].

For developing countries the importance of local context and involvement of local stakeholders during the implementation of systems has been stressed [22]. This is based on a case study on the implementation of an invoice system in the Mozambique Electricity Company. Systems developers need to employ suitable approaches of development that considers the resource constrained situation of Africans and matches their local culture [21]. For this, they proposed what they called a made-in-Nigeria systems development methodology. As introduction of technology to a new local context can involves cultural transfer and mutual learning, we need to understand and value local practices [2]. This is derived from a case study on computerization and networking of branches in the Nigerian banking sector.

Software companies in Nigeria typically have 11-50 staff with an average of 1-5 people in a given job category [24]. The average work experience of IT professionals was one to five years. Most customers for software companies are from domestic private service sector and companies work on a broad variety of platforms, products and languages. The companies had an average of 12 projects with a duration of six months. Companies commonly use in-house tailored software development methods.

\section{Methods}

The objective of this research was to explore the practice of information systems development by software firms in Ethiopia. To achieve this, the Grounded Theory methodology has been employed. The GT method is a qualitative research method that seeks to develop theory that is grounded in data systematically gathered and analyzed (Glaser and Strauss, 2009) [19]. The use of the method was considered relevant for this research as it enables deep understanding of a phenomenon or process in a unique context (Glaser and Strauss, 2009) [19]. There is lack of literature on information system development by software companies in Ethiopia. This makes the local context unique to information system research and the use of the GT method relevant.

\subsection{Research Sites}

This study investigated seven software companies from a population of IT service providers operating in Ethiopia's capital city Addis Ababa. Ethiopia was the 
world's fastest growing economy in 2014 (10.3\%) [26]. The participating companies are small having less than 20 employees to work on development activities except one with around 30 development professionals. The companies years of experience ranges from 5 to 20 years. Companies $\mathrm{A}$ and $\mathrm{B}$ have been in the industry for around 14 to 20 years.

The younger companies such as Company D, Company $\mathrm{E}$ and $\mathrm{F}$ were founded by former employees of the older ones like Companies A, B and $\mathrm{C}$. There are also people who have worked in two or more of the companies in this study. The majority of the companies work on automation of external services and internal business process of different public sector organizations. They mainly involve development of payroll, accounting, finance and human resource information systems. Information systems developed for public services involve systems for tax payment, billing, court management and business licensing. Companies develop systems from scratch and/or customize previously developed systems to the requirements of a new client. Some of the companies are market driven; they develop, market and sell systems to selected private businesses.

Table 1. Software Company and Participant Details

\begin{tabular}{|c|c|c|c|}
\hline Company & Participant Job Title & No. of Interviews & Contract Type \\
\hline A & $\begin{array}{l}\text { Chief Technology Officer } \\
\text { Manager }\end{array}$ & 2 & $\begin{array}{l}\text { Bespoke } \\
\text { Development }\end{array}$ \\
\hline B & $\begin{array}{l}\text { Chief Technology Manager } \\
\text { Operations Manager } \\
\text { Programmer }\end{array}$ & 3 & $\begin{array}{l}\text { Bespoke } \\
\text { Development }\end{array}$ \\
\hline $\mathrm{C}$ & $\begin{array}{l}\text { Manager } \\
\text { Programmer }\end{array}$ & 2 & $\begin{array}{l}\text { Bespoke } \\
\text { Development }\end{array}$ \\
\hline $\mathrm{D}$ & $\begin{array}{l}\text { Manager } \\
\text { Programmer }\end{array}$ & 1 & $\begin{array}{l}\text { Bespoke } \\
\text { Development }\end{array}$ \\
\hline $\mathrm{E}$ & $\begin{array}{l}\text { Senior Programmer/Manager } \\
\text { Senior Programmer }\end{array}$ & 2 & $\begin{array}{l}\text { Bespoke } \\
\text { Development }\end{array}$ \\
\hline $\mathrm{F}$ & $\begin{array}{l}\mathrm{CEO}^{3} \\
\text { Architect }\end{array}$ & 2 & $\begin{array}{l}\text { Bespoke } \\
\text { Development }\end{array}$ \\
\hline $\mathrm{G}$ & $\begin{array}{l}\text { Manager } \\
\text { Scrum Master } \\
\text { Programmer }\end{array}$ & 5 & Outsourcing \\
\hline
\end{tabular}

\subsection{Data Collection}

The research used audio-recorded, open-ended semi structured interviews with 17 software practitioners, as shown in Table 1. The interviews were conducted in a combination of Amharic and English. The interviews were then translated, 
where necessary and transcribed in English. An interview guide was developed based on the software development lifecycle. The interview questions asked focused on the development process used and challenges faced, as shown in Appendix 1 . The average length of interviews was one hour. During the interviews, probing questions were used to explore relevant topics raised by participants. The snowball sampling technique was used to recruit participants for interviews.

\subsection{Data Analysis}

To analyse the interview data, the grounded theory method has been employed [19]. The GT method enables the emergence of theory from data that can explain the study phenomenon in a particular situation. Data analysis in Straussian GT has three coding steps namely open, axial, and selective coding [25]. Open coding was performed to identify key points and concepts in the data. Axial coding was performed to identify the relationships among concepts. Finally, selective coding was conducted to discover the major categories of concepts. Memoing was used to collate information about each major category, bringing together quotations and concepts to form each element of the grounded theory.

\section{Findings}

The grounded theory analysis has resulted in the identification of conceptual categories that emerged from the data which describe the agile practices used, the context in which they are used, their use benefits and challenges of using them by small companies in this research.

\subsection{Using Agile Methods}

Most participants from different companies in this study claimed to use agile methods on projects. This has been described by using terms such as "we internally develop the software agile way" (Chief Technology Officer, Company A); "we do the work agile way" (Chief Technical Manager, Company B); "we use an agile process internally" (Developer and manager, Company D), "our process is the agile-Scrum method" (Manager and Programmer, Company C). In Company $\mathrm{F}$ we observed a full implementation of the Scrum method. Agile methods are used because of the perception that they provide solutions to challenges commonly experienced by the software development companies in the study. By using agile practices, the companies are able to improve requirements elicitation by involving users and quickly constructing product features. It is also perceived that following the waterfall approach cannot work in the existing development context where requirements are vague and user participation is limited. Documentation has little or no importance for the actual development of software due to frequent requirements changes resulting from lack of users knowledge and their limited participation during development. 
Iterative and Incremental Processes The majority of organizations in this study use iterative and incremental development practices as part of their agile processes. Multiple iterations are conducted during requirement elicitation for each module of the system and the modules are developed incrementally. Chief Technical Officer from Company B, for example, stated that "Each of our teams iteratively collect requirements for the assigned software modules and develop them incrementally". Chief Technology officer from Company A has pointed out, "Iteration is important as we can repeatedly develop prototypes and we use them to clarify requirements by involving users during our frequent visit." In Company $\mathrm{D}$, the iterative and incremental approach has been used after software design has been completed:

"after completing the design phase, we try as much as possible to make the development iterative and incremental which is release or build based. We conduct iteration release demonstration every month" (Manager and Programmer, Company D).

Release/Prototype Demonstration During the iterative and incremental process, release demonstrations are provided to validate and enrich user requirements. The release demonstrations are performed weekly, monthly as in Company $\mathrm{C}$ and $\mathrm{D}$ respectively or as required by the development team, which is the case in company B. Release demonstrations are used to enrich and complete requirements based on user feedbacks. They are used for internal purpose; otherwise, product delivery is done on the final release. A participant has pointed out

"during the monthly project reports, we were also providing release demonstrations to the client representatives. They then tell us what new features to include and which ones to exclude" (Senior Programmer and Manager, Company E).

Face to Face Communication The companies in this study organise frequent internal meetings of team members and external meetings with customers. In companies A, C and G, they have daily team meetings. The Chief Technology Officer from Company A stated that:

"each of our development teams conduct a 10 to 15 minutes meeting as their first activity of the day. During this meeting, the team discusses their progress, problems and challenges faced, they also share experience and learn from each otherthis is a good practice we picked from the Scrum methodwe have also weekly meeting with all teams as our ISO standard process requirement."

However, in contrast, the Chief Technical Manager from Company B stated, "we do not need daily team meeting as each team is collocated but we have weekly meeting of all teams." The meetings are used as a platform to discuss progress and challenges. They are also used to enable learning from each other. 
Working Software Working software has a number of advantages for organizations. It enables early understanding of requirements, to monitor if the project is on the right track and meet schedule. By showing something functional to customers, it is possible to motivate them to participate and provide quick feedbacks. Manager and Programmer from Company E emphasized, "our milestone is producing a working module that is acceptable by our customer." Chief Technical Manager from Company B stressed, "we want a method that is product focused; provides the opportunity to start the actual development as quickly or early as possible."

User Involvement and Customer Management Involving users is a common challenge for the companies working on government projects in this study. To address this challenge, the software companies in this research use frequent product feature demonstrations to involve users and collect requirements. Companies $\mathrm{A}, \mathrm{E}$ and $\mathrm{F}$ also have dedicated teams working on client sites. The Manager and Programmer from Company E stated that "we have a customer relations management team which is a technical team working at our customer site with the user to identify variations we should accommodate in our system." There are also practices of setting up client representatives separately for technical and management people as in Company D for example.

\subsection{Contract Challenges}

Participants have identified bureaucracy in government organizations and the tender and contract nature as major barriers to companies use of agile methods and success of projects. Government contracts mandate formal documentation and milestone phase delivery. The contract award criteria are based on the least bid/tender cost and the project schedules are fixed and very short. (Chief Technical Manager, Company B; Manager and Programmer, Company C; Chief Technology Officer, Company A).

"Our big challenges are [government] project tender/bid procedure and contract requirements. We are forced to follow the waterfall cycle, we should produce inception, analysis and design documents based on fixed schedule... project schedules are commonly four to six months" (Chief Technology Officer, Company A).

\subsection{Issues of User Involvement, Requirement and the Waterfall Method}

There is a common problem of shortage of user involvement particularly for government projects. Users are not interested in the project, they are not reachable and they believe software project is not their responsibility. Participants believe that following the waterfall process results in failure mainly due to the difficulty of getting clear and complete requirement during early stage of the project in 
one short phase. There is also limited or shortage of user involvement and they lack knowledge and understanding of software requirement and have difficulty of describing their requirements. Manager and Programmer from Company D has pointed out that "users understand their requirement at implementation." It has also been indicated, "if you follow the waterfall cycle only, you know you will fail... Users start to ask for new and different features at UAT [user acceptance test]. At the end of the day, no one will be willing to sign off the project" (Chief Technology Officer, Company A). On the importance of documentation, Chief Technical Manager from Company B has mentioned, "you should accommodate documentation for payment purpose." Participant indicated the problem of using agile methods stating, "if you purely follow agile you will get no money. So you try to mix them [agile with waterfall]..." (Chief Technology Officer, Company A).

In summary, this research has shown that small companies in the study are working on government projects; they are using agile practices with documentations; there are a number of situational issues affecting the use of agile practices by companies. The next section discussion on how the findings of this research can relate to previous studies.

\section{Discussion}

The participants in our study largely concur with practitioners from the global north who perceive the most important agile features as 'frequent delivery of working software, daily interaction between business people and developers and face-to-face communication' [12]. Most participants in our study have emphasized that incremental prototype demonstration has enabled them to address requirement incompleteness and changes which they believe are difficult or impossible when using the waterfall methodology.

Agile requirement engineering employs iterative approach and intensive face to face communication with the customer [10] [20]. Through the close collaboration between developers and customers, the iterative approach to agile requirement engineering improves requirement understandability and completeness. In addition, prototyping and release demonstration have also been used by companies in our study to support requirement elicitation by reducing the challenges of involving users in projects. However, in our study, product delivery is done at the end while software construction or customization may begin at early development stage with frequent feature demonstration for user feedback.

Lack of user participation has been identified as the major barrier to organizations use of agile requirement engineering practices [10]. Participants in our research try to address a lack of user participation by using frequent product feature demonstrations and having teams work at the customer site.

It has been argued that formal documentation of requirements does not eliminate the need for frequent communication [10]. However, the stringent requirement for extensive documentation imposed by government projects in our study has been identified as a major challenge. Most participants in our research be- 
lieve that using agile with documentation is costly and time consuming as it creates repetition of work.

Tailored approaches that mix agile practices with plan-based approaches have been observed in many organizations [18] [11] [5]. Those studies provide evidence of pragmatic approaches to process tailoring. Paradoxically, participants in this research perceive that there are extreme differences between agile and waterfall approaches. Despite constraints placed on participating software companies, for example by bureaucratic government clients, participants tended to adopt a somewhat dogmatic view of the differences between agile and plan-based approaches.

Agile methods can be used to improve job satisfaction, productivity, and increased customer satisfaction while its success requires focusing on individual and social issues [16]. The findings of our research indicated that agile use enable companies to improve participation of customers and manage requirements through release demonstration. Cross functional teams also improve team motivation by providing team autonomy. This in turn can improve staff retention in a labour market with pronounced shortages of skilled people.

Though agile methods are believed to be particularly applicable to small software companies [16], our results indicate that they are finding adoption of the method difficult. Government demands for extensive documentation and reporting requirements impose a barrier to agile procurement adoption in the U.S. [23]. Participants in our study believe that agile conflicts with contracts that have milestone and extensive documentation requirements. Critical success factors for agile use [13] hold for the companies in our study too. For example, they do not have personnel to fill all agile roles. The findings of our research also suggest that there are gaps in practically using agile practices in the study organizations regardless of the widespread perception of the importance of the method.

Successful agile adoption for larger projects requires a disciplined approach [1]. However, scrum related roles, ceremonies and artefacts are missing from the methods adopted by companies in our study because of a lack of staff and finance as well as the lack of capacity more generally in the local context.

\section{Conclusions}

This research has investigated software development by smaller software companies in sub-Saharan Africa. The research has adopted the grounded theory method to analyse audio-recorded semi structured interview data collected from 17 participants from 7 software companies in Addis Ababa, Ethiopia, which were recruited using the snowball sampling technique.

Our findings focus on three main areas: agile practices used in small companies, the type of projects they use them on, the benefits and barriers of using agile. Software companies use agile methods to address development problems that can arise if they follow the waterfall process. Iterative methods, which provide the opportunity to work closely with users, enable vendors to get valid 
and complete requirements from clients. During each iteration, continuous tests and demonstrations of working software earn customers' trust, encouraging their participation in projects and managing their expectations.

By using agile methods companies are trying to create motivated and cohesive teams by allowing them to be self-managed and self-organized. Frequent team meetings create a platform to share experience, collaborate and reflect on the challenges they face. Companies in our study have strong focus on starting software construction earlier in the development process. Participants in our study do not give much attention and importance to documentation and yet are often obliged to produce extensive documentation to comply with government contract terms.

This study makes three main contributions to literature on information system development in sub-Saharan Africa. First, the research discovered that there is a widespread awareness and use of agile practices. Participants have stressed that the focus on working software enabled companies to motivate user involvement, improve requirement understanding, gain customer trust and increase market-share for their product. Moreover, companies believe that agile use enables staff retention as a result of motivation from the autonomy it provides to the team. Collaborative working in cross-functional teams also supports staff retention. The barriers companies face in using agile practices on government projects have also been identified.

Second, it is interesting that companies in this study are working on government projects. Such projects have fixed price contracts with a pre-determined delivery schedule and formal document approvals.

Third, the study has shown the barriers to the practical use of agile method to the level required in companies. We have provided empirical evidence on how agile adoption by companies can be influenced by the nature of contract, nature of client, user involvement, shortage of finance and skill.

Further research is required on how agile methodologies can be tailored for use in a developing country context, for example investigating how agile practices are mixed with plan-based approaches in African and other developing countries.

\section{References}

1. Ambler, S.W., Lines, M.: Disciplined Agile Delivery: A Practitioner's Guide to Agile Software Delivery in the Enterprise. IBM Press (May 2012)

2. Bada, A.O.: Local Adaptations to Global Trends: A Study of an IT-Based Organizational Change Program in a Nigerian Bank. The Information Society 18(2), 77-86 (Mar 2002)

3. Bass, J.M.: Influences on Agile Practice Tailoring in Enterprise Software Development. In: Agile India. pp. 1 - 9. IEEE, Bangalore, India (Feb 2012)

4. Bass, J.M.: How product owner teams scale agile methods to large distributed enterprises. Empirical Software Engineering 20(6), 1525 - 1557 (2015)

5. Bass, J.M.: Artefacts and agile method tailoring in large-scale offshore software development programmes. Information and Software Technology 75, 1-16 (Jul 2016) 
6. Blake, E., Tucker, W.: Socially Aware Software Engineering for the Developing World. In: Cunningham, P., Cunningham, M. (eds.) Proceedings IST-Africa 2006. Pretoria, South Africa (2006)

7. Boehm, B.: Some future trends and implications for systems and software engineering processes. Syst. Eng. 9(1), 1-19 (Jan 2006)

8. Boehm, B., Turner, R.: Management challenges to implementing agile processes in traditional development organizations. IEEE Softw. 22(5), 30-39 (Sep 2005)

9. Campanelli, A.S., Parreiras, F.S.: Agile methods tailoring a systematic literature review. Journal of Systems and Software 110, 85 - 100 (2015), http://www.sciencedirect.com/science/article/pii/S0164121215001843

10. Cao, L., Ramesh, B.: Agile Requirements Engineering Practices: An Empirical Study. IEEE Software 25(1), 60-67 (Jan 2008)

11. Cardozo, E.S.F., Neto, J.B.F.A., Barza, A., Frana, A.C.C., da Silva, F.Q.B.: SCRUM and Productivity in Software Projects: A Systematic Literature Review. In: Proceedings of the 14th International Conference on Evaluation and Assessment in Software Engineering. pp. 131-134. EASE'10, British Computer Society, Keele University, UK (Apr 2010)

12. de Cesare, S., Lycett, M., Macredie, R.D., Patel, C., Paul, R.: Examining perceptions of agility in software development practice. Commun. ACM 53(6), 126-130 (Jun 2010)

13. Chow, T., Cao, D.B.: A Survey Study of Critical Success Factors in Agile Software Projects. J. Syst. Softw. 81(6), 961-971 (Jun 2008)

14. Clutterbuck, P., Rowlands, T., Seamons, O.: A case study of sme web application development effectiveness via agile methods. Electronic Journal of Information Systems Evaluation pp. 13-26 (2009)

15. Conboy, K., Fitzgerald, B.: Method and developer characteristics for effective agile method tailoring: A study of xp expert opinion. ACM Trans. Softw. Eng. Methodol. 20(1), 2:1-2:30 (Jul 2010)

16. Dybå, T., Dingsøyr, T.: Empirical studies of agile software development: A systematic review. Information and Software Technology 50(910), 833-859 (Aug 2008)

17. Dybå, T., Dingsøyr, T.: What do we know about agile software development? IEEE Software 26(5), 6-9 (2009)

18. Fitzgerald, B., Hartnett, G., Conboy, K.: Customising agile methods to software practices at Intel Shannon. European Journal of Information Systems 15(2), 200213 (Apr 2006)

19. Glaser, B.G., Strauss, A.L.: Discovery of Grounded Theory: Strategies for Qualitative Research. Aldine, Chicago, IL., USA (1967)

20. Inayat, I., Salim, S.S., Marczak, S., Daneva, M., Shamshirband, S.: A systematic literature review on agile requirements engineering practices and challenges. Computers in Human Behavior 51, Part B, 915-929 (Oct 2015)

21. Korpela, M., Soriyan, H., Olufokunbi, K., Mursu, A.: Made-in-Nigeria systems development methodologies: An action research project in the health sector. Information Technology in Context: Studies from the perspective of developing countries pp. 134-152 (2000)

22. Macome, E.: On the Implementation of an Information System in the Mozambican Context. In: Korpela, M., Montealegre, R., Poulymenakou, A. (eds.) Organizational Information Systems in the Context of Globalization, pp. 169-184. No. 126 in IFIP The International Federation for Information Processing, Springer US (2003)

23. Mergel, I.: Agile innovation management in government: A research agenda. Government Information Quarterly 33(3), 516-523 (Jul 2016) 
24. Soriyan, H.A., Heeks, R.: A Profile of Nigeria's Software Industry. Tech. Rep. 21, University of Manchester, Global Development Institute, Manchester (2004), http://www.gdi.manchester.ac.uk/research/publications/workingpapers/di/di-wp21/

25. Strauss, A., Corbin, J.: Basics of Qualitative Research: Techniques and Procedures for Developing Grounded Theory. SAGE Publications, Inc, Thousand Oaks, 2nd revised edition edition edn. (Nov 1998)

26. United Nations Economic Commission for Africa: Greening Africa's Industrialization: Economic Report on Africa 2016. Tech. rep., Addis Ababa, Ethiopia (2016), http://www.uneca.org/publications/economic-report-africa-2016

27. UNTAD: Information Economy Report 2012, http://unctad.org/en/pages/Publication Webflyer.aspx?publicationid=271, [accessed 30-10-2016]

28. Wang, X., Conboy, K., Pikkarainen, M.: Assimilation of agile practices in use. Information Systems Journal 22(6) (2012)

\section{Appendix 1 - Illustrative Interview Guide}

1. Please tell me about yourself: your educational and professional background, years of experience and your role at your company.

2. Can you please tell me about your interesting development projects? What are your roles and responsibilities in those projects?

3. What are the team size and duration of the projects?

4. What software development processes and practices do you use in your company?

5. How do you collaborate/communicate with team members, managers and customers?

(a) How frequently (weeks, months) do meetings take place between team members, customers and management?

6. What artefacts/ project specifications and documents (for e.g. requirement, design, user) do you produce or use during software development?

7. What project guidelines or standards do you have or use at your company for: coding, communication, design, testing and documentation etc.

8. What difficulties do you face in carrying out your project responsibilities?

(a) In relation to teamwork

(b) In relation to software development process used at your organization

(c) In relation to organizational management

(d) In relation to customers

9. How do these difficulties or issues influence successful completion of software projects?

10. What improvements do you recommend on the areas of difficulties?

11. Is there anything that you think we should have discussed? 